\title{
Issues related to the interviewer's ability to elicit reports of abuse from children with an intellectual disability: A review
}

\author{
Natalie M Aarons and Martine B Powell ${ }^{\star}$
}

Children with intellectual disabilities constitute a high proportion of all child abuse victims, with most estimates ranging from 30-40\% (Conway 1994; Goldman 1994) ${ }^{1}$. Despite their high risk of abuse, children with intellectual disabilities are less likely than mainstream children to report abuse (Goldman 1994), and of those incidents that are reported, few cases progress to court (Henry \& Gudjonsson 1999). The relatively high rate and under-reporting of abuse among these children is related in part to their cognitive and language limitations (Goldman 1994; Henry \& Gudjonsson 1999). Children with intellectual disabilities tend to have a high reliance on others for personal care, and are thereby exposed to numerous (potentially abusive) carers (Conway 1994). Further, the cognitive and language limitations experienced by these children can make it difficult for them to communicate their experiences (Westcott 1994; Westcott \& Jones 1999), and to resist highly leading or suggestive questioning (Dent 1986; Gudjonsson 1992). Finally, children with intellectual disabilities may be unable to discriminate between appropriate and inappropriate physical contact by adults (Goldman 1994).

Despite the above concerns, the under-representation of children with intellectual disabilities in the criminal justice system is due to more than just cognitive and language factors related to this group. While it is more difficult to detect abuse and to elicit accurate and detailed evidence from these children compared to their mainstream peers, research clearly indicates that children with intellectual disabilities can provide forensically relevant information if techniques are implemented to overcome their communication impairments (see Henry \& Gudjonsson 1999; Perlman et al 1994). The exclusion of children with

* Natalie Aarons is a postgraduate psychology student at Deakin University (Melbourne Campus). She is currently conducting a research project that examines the experiences of police when interviewing children with an intellectual disability. Dr Martine Powell is the coordinator of the Doctorate of Psychology (Forensic) and is a Senior Lecturer at the School of Psychology at Deakin University (Melbourne Campus). She has conducted research on eyewitness memory and investigative interviewing since 1989 and regularly trains police, lawyers and social workers in interviewing techniques throughout Australia. Any correspondence about this paper should be directed to Dr M Powell at School of Psychology, Deakin University, 221 Burwood Hwy, Burwood. VIC.3125, Australia. Email: mbpowell@deakin.edu.au.

1 In this discussion, 'children' are referred to as persons less than 18 years of age. A child with 'intellectual disability' is referred to as one who is showing evidence of significant deficits in cognitive functioning and adaptive behaviours (Intellectually Disabled Persons Act 1986). 
intellectual disabilities from the court may therefore be related to investigative interviewers' (e.g., police officers and child protection workers) ability and willingness to employ information-gathering techniques that both minimise the communication difficulties experienced by these children and maximise the amount and accuracy of the information obtained. This is dependent on several factors including the interviewer's attitude toward and awareness of the child's strengths and weaknesses, the culture of the interviewer's workplace or organisation, and the amount of training and experience the interviewer has in working with this population. However, despite the relevance of these factors, there has been surprisingly little discussion in the current literature on how such factors influence interviewers' ability to elicit forensically relevant evidence from children with intellectual disabilities. Indeed, most of the literature has focused on describing the communication barriers faced by children with intellectual disabilities when participating in interviews, rather than discussing what is needed to promote change in current interviewing practice.

This paper addresses this concern by integrating knowledge on the vulnerability of interviewees with intellectual disabilities with literature on investigative interviewing techniques and social/organisational psychology. The aim of this paper is to highlight and explore issues specific to the interviewers' situation that impact upon the quality of evidence obtained from children with intellectual disabilities. The factors discussed in this paper include: (i) the suitability of current 'best-practice' interviewing guidelines, (ii) the impact of prejudices towards people with intellectual disabilities, and (iii) the impact of organisational pressures. This paper describes each of these factors and provides a rationale for their relevance to the interviewing of children with intellectual disabilities Recommendations for future research are also outlined.

\section{Suitability of current 'best practice' interviewing guidelines}

For a person to be charged and convicted of an offence, highly specific and detailed evidence is usually required by the court. In cases of suspected child abuse, a large part of this evidence is usually a written or videotaped statement about the abuse from the victim, who is often the only witness to the alleged crime (McGough 1994). In particular, witnesses are required to identify the time and place of at least one of the incidents and the specific acts of abuse experienced (see $S \vee R$ 1989). Contextual factors must also be recalled, such as what clothing was worn, what the alleged offender did and said, and where other people were during the incident(s) (Powell \& McMeeken 1998). This requirement (referred to as particularisation) poses a problem for the investigation of child abuse because the identification of highly specific details related to one abusive incident is a difficult task for any witness, but is especially difficult when the witness has limited cognitive and language abilities (see Roberts \& Powell 2001 for a review of this issue). Without competent interviewing strategies, information provided by a child or other vulnerable witness is less likely to be accurate, relevant and detailed (Ceci \& Bruck 1995).

There is general consensus among researchers as to which interviewing strategies maximise the accuracy, detail and reliability of information obtained from child witnesses (see Home Office and Department of Health 1992; Poole \& Lamb 1998; Wilson \& Powell 2001). Overall, the central aim of the forensic interview is to allow the child to provide an interruption-free account of the incident in his/her own words and at his/her own pace. This is known as a 'free narrative account', which is usually preceded with a single non-focused, open-ended question (e.g., 'Tell me everything you can remember about ... from beginning to end.') (Wilson \& Powell 2001). Subsequently, minimal nonverbal encouragers (e.g., 
head nods, pauses) and further open-ended questions (e.g., 'Tell me more about that', 'What happened then?') are utilised to steer the interviewee to the next point in the story, or to gently encourage the interviewee to be as informative and detailed as possible without dictating what specific information is required (Powell \& Thomson in press). While the information provided in free narrative reports is generally highly accurate, it rarely includes all the specific details required for the investigation (Dent \& Stephenson 1979). Thus, once free narrative is exhausted, specific questions are usually necessary to yield more precise information or to seek clarification, even though such questions usually result in higher error rates (Ceci \& Bruck 1993).

It is important to note that the above guidelines apply to all witnesses, including adult offenders (Fisher \& Geiselman 1992), very young children (Wilson \& Powell 2001), persons with intellectual/physical disabilities (Home Office and Department of Health 1992), and persons who do not speak English as a first language (Powell 2000). In other words, no specific set of guidelines has been articulated for the interviewing of children with intellectual disabilities by investigative interviewers. However, many of these children have unique needs for which the current investigative interviewing recommendations may not adequately accommodate. For example, some children with intellectual disabilities experience significant auditory impairments and motor control difficulties that affect their speech production (Ericson et al 1994). To overcome such difficulties, these children may employ a combination of speech and sign language, or an alternative method of communication, such as communication boards. With such communication systems, it is not always possible to obtain a detailed, spontaneous free narrative account of an event (Westcott 1994). Further, children with intellectual disabilities may have little experience responding to open-ended questions (Marchant \& Page 1992). Hence, even though their responses to open-ended questions are quite accurate, children with intellectual disabilities are less likely to volunteer specific information in response to these questions compared to children of equivalent chronological or mental age (Agnew 2002).

The issues discussed above have led some interviewing instructors to question the degree to which the currently-espoused questioning strategies are suitable for interviewing children with intellectual disabilities (see Wilson \& Powell 2001). If interviewing strategies are not tailored to suit the child's style of communication, then the poor quality evidence produced could be unfairly perceived as a lack of competency or credibility on the child's part (Ericson et al 1994). The paucity of research investigating the effectiveness of various question types with children with intellectual disabilities currently precludes the development of clear guidelines for maximising the reliability of their evidence. However, even if such guidelines were available, these alone would not be sufficient to improve the quality of evidence obtained from children with intellectual disabilities.

Interviewers need to know not only how to tailor an interview to the special needs of these children, but to decide when a deviation from the recommended 'best-practice' guidelines is required. Currently, screening tools are available for detecting intellectual disability as opposed to mental illness (e.g., Hayes Ability Screening index). However, further research is needed to detect the degree to which people who meet the diagnostic category of 'intellectually disabled' can cope with the recommended style of questioning outlined above. For instance, some legal agencies have funded the development of guidelines (by linguists) to determine whether a person of a different cultural group is sufficiently competent to participate in an interview without the assistance of an interpreter (Cooke \& Wiley 1999). While interviewers also need to alter their style of questioning to accommodate the communicative requirements of children with intellectual disabilities, 
little information is available to professionals outlining how and when to do so, especially among children who use augmentative and alternative communication systems.

To remedy this issue, three changes would be required. First, more empirical research needs to be conducted to determine the effectiveness of different question types on the quality of information obtained from children with varying degrees of disability. While some prior research in this area exists, most of this work has focused on children with mild or borderline intellectual ability (see Dent 1986; Henry \& Gudjonsson 1999). Second, government agencies and professional groups need to invest in the translation of research findings into interviewing guidelines. Such guidelines need to be developed by professionals with highly-specialised expertise (i.e., knowledge about all aspects of human development, eyewitness memory research as well as police and court procedures), not just expertise in intellectual disability.

Finally, many children with intellectual disabilities are not used to responding to openended questions in the home or school setting (Agnew 2002). As such, increasing the exposure of these children to this type of questioning prior to the actual interview is likely to be beneficial. For example, interviewing instructors recommend that a pre-interview assessment be conducted where the child is encouraged to give an uninterrupted account during the rapport-building stage of the interview about an innocuous event (e.g., a recent holiday or birthday party; Lamb et al 2001). This provides the interviewer with a sense of the child's ability to recall past events (i.e., the level of detail that can be provided), and it also familiarises the child with a style of interaction that is open-ended and child-centered. Furthermore, providing children with intellectual disabilities with a clear explanation of the type of interaction that is expected during investigative interviews may also be beneficial. Indeed, most current 'best-practice' interview guides suggest that prior to forensic interviews, all child witnesses should be provided with clear instructions about the conversational rules governing such interviews (e.g., the need to provide specific details, to avoid guessing or making up responses, and that using the phrase 'I don't know' is acceptable) (Aldridge \& Wood 1998; Poole \& Lamb 1998; Wilson \& Powell 2001). These suggestions have been found to increase the amount and accuracy of information that the child provides in response to open-ended questions about the alleged offence (Saywitz et al 1999; Sternberg et al 1997).

\section{The impact of prejudices toward children with intellectual disabilities}

Another issue related to the under-reporting of abuse and poor quality of evidence obtained from children with intellectual disabilities is the prejudices frequently held toward them by interviewers. While negative stereotypes about people with intellectual disabilities are fairly widespread among the general public (Westcott \& Cross 1996), there is an abundance of literature to support the social fact that prejudices among investigative interviewers leads these professionals to underestimate the ability of individuals with intellectual disabilities to give useful evidence (Brennan \& Brennan 1994; Marchant \& Page 1997; Westcott 1994). Such professional judgements are considered biased because they are often formed prior to a thorough assessment of the children's strengths and weaknesses and their preferred method of communication. For example, Brennan and Brennan (1994) conducted a survey of police officer attitudes to people with intellectual disabilities in New South Wales (Australia). This study revealed that these professionals (as a group) tended to believe that the cognitive, verbal and concentration difficulties typically experienced by individuals 
with intellectual disabilities rendered them unable to provide credible and uncontaminated evidence (Brennan \& Brennan 1994).

Similar studies have found that police officers, like persons in the general community, tend to stereotype people with intellectual disabilities, and these stereotypes influence police responses to these individuals' reports of abuse (Keilty \& Connelly 2001; McAfee et al 2001). Investigative interviewers who possess negative and conclusive opinions about individuals with intellectual disabilities tend not to pursue investigations to their full potential (Milne \& Bull 1999). They may ignore or overlook potentially relevant details, and they tend to be close minded, relying on a leading style of questioning that is unlikely to be admissible in court (Ceci \& Bruck 1995).

Negative beliefs relate not only to the witness' competence but also to professionals' beliefs about their ability to overcome barriers of communication. For example, many investigative interviewers (even those who are highly competent and experienced) typically describe feelings of insecurity and anxiety when faced with the task of interviewing a person with an intellectual disability (Brennan \& Brennan 1994; NSPCC et al 2001). These feelings seem to be exacerbated when the child being interviewed has a communication impairment or uses an unfamiliar method of communication (Marchant \& Page 1997). Further, negative stereotypes held about people with intellectual disabilities provide little incentive for interviewers to learn ways of overcoming barriers to communication with these witnesses. In other words, the negative stereotype becomes self-fulfilling. This need not be the case. Any witness (even one with severe communication difficulties) can potentially report forensically relevant and accurate information about a situation or event, provided (s)he encoded and stored the particular event in memory and is interviewed under appropriate conditions (Dent 1986; Ericson et al 1994; Gordon et al 1994; Henry \& Gudjonsson 1999).

The feelings of inadequacy and poor confidence experienced by professionals when dealing with children with intellectual disabilities are likely to be a consequence of inadequate information, training, and practice in communicating with this group (Westcott \& Cross 1996). Most investigative and evidential interviewers do not receive training in how to interview children with special needs (Aldridge \& Wood 1998), and of those that do, most believe that this falls short of what is necessary to interview these children competently (Brennan \& Brennan 1994; Davies et al 1998; Westcott \& Davies 1996). Given that the interviewing of children with intellectual disabilities requires specialised knowledge yet only a small amount of training and practice is usually devoted to this, it is not surprising that interviewers feel under-prepared and nervous when they are required to interview these children. Consequently, professionals' ability to elicit useful accounts of an offence from children with intellectual disabilities will be poor, and may be misattributed to a lack of competence in the child.

As prejudices against people with disabilities are deeply entrenched within our society, implementing changes to current interviewing practice is a challenging task. Westcott and Cross (1996) contend that societal structures and their functioning contribute to the development and perpetuation of these prejudices and attitudes. These societal factors have broad organisational implications, such as limits on the amount of funding allocated for researchers to explore techniques for interviewing children with intellectual disabilities, and for the specialised training of interviewers. Such prejudices can also bias jury decisions (Clarke 2000). The court's regular failure to accept the accounts of these children as acceptable (Brennan \& Brennan 1994) may reduce the persistence of police and child protection workers to investigate cases of abuse involving a child with an intellectual 
disability. If the case has a poor likelihood of progressing to court, interviewers may view their attempts to obtain evidence as a wasteful pursuit, even if such information may be used by human service agencies to prevent further abuse by changing the child's situation. In order to increase the reporting and detection of abuse among children with intellectual disabilities, many professional groups (and society as a whole) must challenge the existing elements and functions that contribute to the unequal treatment of this group (Westcott \& Cross 1996).

\section{The influence of organisational pressures on the quality of evidence elicited}

Even if an investigative interviewer is motivated to tailor his/her questioning to the needs of children with intellectual disabilities, organisational pressures may play a role in limiting the quality of evidence obtained from this vulnerable group. Such issues include restrictions in the time needed to obtain useful evidence, financial pressures limiting the amount of 'refresher' training and practice in interviewing children with intellectual disabilities, and a lack of knowledge and training among workplace supervisors. The relevance of each of these factors is discussed below.

First, pressure from workplace supervisors to obtain information as quickly as possible to pursue other aspects of the investigation, and (in the case of the police force) to improve charge rates, may influence interviewers' ability to elicit accurate and detailed accounts of abuse from children with intellectual disabilities (Ainsworth 1995; Reiner 1992). In fact, Kebbell and Milne (1998) found that nearly half of surveyed police officers felt that they were rarely given as much time as they needed to conduct their interviews. This perceived lack of time may explain the poor quality of some police interviews, where officers who are hurried or anxious interrupt witness' accounts or introduce highly specific, closed and leading questioning in their interviews to cut down time (Kebbell \& Milne 1998). Such questions reduce the quality of the evidence and the likelihood of a successful conviction if prosecution goes ahead with the case (Ceci \& Bruck 1995). The problem of time restrictions is compounded in interviews with children with intellectual disabilities, who generally take longer to provide their account in their own words compared to mainstream children (Marchant \& Page 1997). Further, the reports of children with intellectual disabilities are more likely to be contaminated by specific, closed and leading questioning (Dent 1986; Henry \& Gudjonsson 1999).

A further organisational issue preventing interviewers from obtaining accurate and detailed evidence from children with intellectual disabilities may be financial pressures restricting the provision of appropriate training and practice to interviewers. As previously indicated, few investigative and evidential interviewers receive specialised training in the interviewing of children with intellectual disabilities. However, research demonstrates that practice and critical feedback of newly-learned skills are the only reliable predictors of a good investigative interviewer (Lamb et al 2002a; Lamb et al 2002b). This requires the establishment of ongoing refresher training courses to update and maintain the skills of interviewers, not merely a one-off course (Powell in press). A lack of financial resources may also mean that training teams are prevented from employing expert consultants who can educate interviewers about how to overcome the barriers of communicating with children with intellectual disabilities (Davies et al 1998). Finally, lack of funding prevents access to handbooks, videos, and journals that interviewers can turn to for additional guidance about types of disabilities and alternative communication methods. As children with intellectual disabilities make fewer disclosures of abuse than their mainstream peers 
(Goldman 1994), professionals do not interview these children as often as mainstream children. As such, any skills acquired during training on how to interview children with intellectual disabilities would be rapidly forgotten if financial restrictions prevent interviewers' access to the resources necessary for maintaining their skills (Powell in press). The dilemma associated with increasing funding for professional development in this area is that most organisations must work within a cost-effective framework and therefore allocate the majority of financial resources to areas with the highest priority. In the police force, for example, child protection work (which is typically afforded low status relative to other areas of policing) must compete with other specialist units for funding (Adams \& Hendry 1996; Davies et al 1998).

A final organisational issue impacting upon the elicitation of reliable and useful evidence from children with intellectual disabilities is the level of knowledge about interviewing held by workplace supervisors. It is often the case that supervisors or team leaders in the area of child protection do not attend training programs designed to update their skills in interviewing children. This is because they tend to be more experienced (have undergone training before), and also because their supervisory role means they have less opportunity to conduct interviews compared to their junior staff (Davies et al 1998; Powell 2002). The problem, however, is that experience in the field and prior training are not good predictors of current performance in interviewing children (Warren et al 1999). Techniques taught in training evolve from year to year as experts reveal new research findings and explore methods of questioning. Indeed, guidelines for interviewing now are quite different to those five years ago, particular in those states where videotaped interviews (as opposed to written statements) have recently been introduced (Wilson et al 1998). The knowledge of workplace supervisors is relevant to the quality of interviews with children with intellectual disabilities for several reasons.

First, supervisors are usually required to provide feedback to their junior staff regarding their interviewing performance. However, without, up-to-date training, supervisors may actually provide feedback that conflicts with those skills taught in recent training programs. Second, without up-to-date knowledge of the content taught in training programs, team leaders are unlikely to promote ongoing refresher training and practice opportunities, and may continue to exert unreasonable time pressures on their officers. Third, a lack of current knowledge may result in the use of obsolete interviewing strategies on those rare occasions where supervisors themselves interview child witnesses. In our experience, these are some of the most common complaints among participants of investigative interviewer training courses.

\section{Summary and future research directions}

Despite their increased risk of abuse compared to mainstream children, child witnesses with intellectual disabilities are under-represented within the criminal justice system (Henry \& Gudjonsson 1999). This paper has described three main factors that are likely to impact on the lack of reporting and quality of evidence obtained from children with intellectual disabilities, apart from the cognitive and language difficulties often presented by these children. First, little research has explored how applicable the current 'best practice' guidelines are to the interviewing of children with intellectual disabilities. As a result, no clear guidance exists in the literature regarding when and how to tailor interviews to suit these children's needs. Second, many negative stereotypes exist among police and other legal professionals about the ability of children with intellectual disabilities to provide forensically relevant evidence. Professionals also possess negative beliefs regarding their 
own skill and ability to elicit accurate and detailed evidence from these children. Finally, organisational demands on the interviewer, such as time and funding restraints, and the lack of ongoing training of supervisors, are likely to be implicated in the poor quality evidence often elicited from children with intellectual disabilities.

As highlighted throughout this paper, the issues discussed above are complex and intertwined. For example, the provision of specific guidelines for the interviewing of children with intellectual disabilities is dependent on funding for research and training. Such research and training, in turn, is contingent on prevailing attitudes or biases toward the value of such work and its implications for practice. Biases or prejudices are directly influenced by knowledge and awareness of disability, and training and practice in how to work with these children. However, while each of these components is likely to play a part in the problem, the extent or contribution of each element and the best way to bring about change is not yet known. Indeed, a large part of the material that constituted this review was obtained from discussion papers written by researchers and instructors in the area of child investigative interviewing and disability, rather than on research that has directly explored the impact of these issues on interviewing practice.

So what type of ongoing research is needed to improve the quality of evidence obtained from children with intellectual disabilities? First, ongoing quantitative research may be required to explore the effectiveness of various questioning strategies in obtaining accurate and detailed evidence from children with varying levels of intellectual impairment. This will provide interviewing instructors and researchers with knowledge about the degree to which current interviewing guidelines are applicable to children with intellectual disabilities. Such research will provide an empirical basis to support amendments to these guidelines. With regard to the impact of prejudices, qualitative research (based on face-toface interviews with professionals rather than scientific experiments per se) is needed to gain an up-to-date understanding of interviewers' perceptions of, and experiences with, children with intellectual disabilities. Further, this research will help to gain a full sense of the precise organisational pressures that are currently placed on interviewers and to gain insight into the best way to implement change within each particular professional group. Such qualitative research will no doubt highlight new issues (i.e., those not already identified in this paper) that may be contributing to the poor quality of evidence obtained from children with intellectual disabilities.

While this paper has painted a pessimistic picture of the quality of interviews with children with intellectual disabilities who are victims of abuse, prior research in the area of interviewing children in general suggests that interviewing practices can (and will) be improved (Orbach et al 2000; Sternberg et al 2001; Lamb et al 2002b). Indeed, many local and international researchers have already started to move their attention away from the topic of how to conduct interviews to an examination of the factors that are needed to promote and maintain good interviewers. The results of such research have already been instrumental in improving the quality of interviews involving mainstream children (see Powell, in press, for review). It is vital that professional groups see the value in participating in research involving the interviewing of children with intellectual disabilities and challenge the existing elements and functions that contribute to the unequal treatment of this group. Increasing interviewers' awareness of the issues presented in this paper will aid in the development of strategies to improve the status of child witnesses with intellectual disabilities, as well as the reporting and detection of abuse among this group. 


\section{LIST OF CASES}

$S \vee R$ (1989) 89 ALR 321.

\section{REFERENCES}

Adams, C \& Hendry, E (1996) 'Challenges to police training on child protection', Child Abuse Review, vol 5, pp 70-72.

Agnew, S (2002) Intellectually disabled children as witnesses: Which questions elicit the most accurate information from this vulnerable group? Unpublished doctoral thesis, Deakin University, Melbourne, Victoria, Australia.

Ainsworth, P (1995) Psychology and policing in a changing world, Wiley, West Sussex.

Aldridge, M \& Wood, J (1998) Interviewing children: A guide for child care and forensic practitioners, Wiley, Chichester.

Brennan, M \& Brennan, R (1994) Cleartalk: Police responding to intellectual disability, Criminology Research Council, New South Wales.

Ceci, S \& Bruck, M (1993) 'Suggestibility of the child witness: A historical review and synthesis', Psychological Bulletin, vol 113, no 3, pp 403-439.

Ceci, S \& Bruck, M (1995) Jeopardy in the courtroom: A scientific analysis of children's testimony, American Psychological Association, Washington.

Clarke, J (2000) 'The social psychology of jury nullification', Law and Psychology Review, vol 24, pp 39-57.

Conway, R (1994) 'Abuse and intellectual disability: A potential link or an inescapable reality?', Australian and New Zealand Journal of Developmental Disabilities, vol 19, no 3, pp 165-171.

Cooke, M \& Wiley, E (1999) Interpreter need guidelines, North Australian Aboriginal Legal Aid Service, Darwin.

Davies, G, Marshall, E \& Robertson, N (1998) Child abuse: Training Investigative Officers. Police Research Series Paper 94, Home Office Policing and Reducing Crime Unit, London.

Dent, H (1986) 'An experimental study of the effectiveness of different techniques of questioning mentally handicapped child witnesses', British Journal of Clinical Psychology, vol 25, pp 13-17.

Dent, H \& Stephenson, G (1979) 'An experimental study of the effectiveness of different techniques of questioning child witnesses', British Journal of Social \& Clinical Psychology, vol 18, pp 41-51. 
Ericson, K, Perlman, N \& Isaacs, B (1994) 'Witness competency, communication issues and people with developmental disabilities', Developmental Disabilities Bulletin, vol 22 , no 2 , pp 101-109.

Fisher, R \& Geiselman, R (1992) Memory-enhancing techniques for investigative interviewing: The Cognitive Interview, Thomas, Springfield, Illinois.

Goldman, R (1994) 'Children and youth with intellectual disabilities: Targets for sexual abuse', International Journal of Disability, Development and Education, vol 41, no 2, pp 89-102.

Gordon, B, Jens, K, Hollings, R \& Watson, T (1994) 'Remembering activities performed versus those imagined: Implications for testimony of children with mental retardation', Journal of Clinical Child Psychology, vol 23, no 3, pp 239-248.

Gudjonsson, G (1992) The psychology of interrogations, confessions and testimony, Wiley, West Sussex.

Henry, L \& Gudjonsson, G (1999) 'Eyewitness memory and suggestibility in children with mental retardation', American Journal on Mental Retardation, vol 104, no 6, pp 491-508.

Home Office and Department of Health (1992) Memorandum of good practice on video recorded interviews with child witnesses for criminal proceedings, HMSO, London.

Kebbell, M \& Milne, R (1998) 'Police officers' perceptions of eyewitness performance in forensic investigations', The Journal of Social Psychology, vol 137, no 3, pp 323-330.

Keilty, J \& Connelly, G (2001) 'Making a statement: An exploratory study of barriers facing women with an intellectual disability when making a statement about sexual assault to police', Disability \& Society, vol 16, no 2, pp 273-291.

Lamb, M, Orbach, Y, Sternberg, K, Esplin, P \& Hershkowitz, I (2001) 'The effects of forensic interview practices on the quality of information provided by alleged victims of child abuse', in Westcott, H, Davies, G \& Bull, R (eds) Children's testimony: Psychological research and forensic practice, Wiley, Chichester.

Lamb, M, Sternberg, K, Orbach Y, Esplin, P \& Mitchell, S (2002a) 'Is ongoing feedback necessary to maintain the quality of investigative interviews with allegedly abused children?', Applied Developmental Science, vol 6, pp 35-41.

Lamb, M, Sternberg, K, Orbach, Y, Hershowitz, I, Horowitz, D \& Esplin, P (2002b) 'The effects of intensive training and ongoing supervision on the quality of investigative interviews with alleged sex abuse victims', Applied Developmental Science, vol 6, pp 114 125 .

Marchant, R \& Page, M (1992) Bridging the gap: Child protection work with children with multiple disabilities, NSPCC, London.

Marchant, R \& Page, M (1997) 'The Memorandum and disabled children' in Westcott, H \& Jones, J (eds) Perspectives on the Memorandum: Policy, practice and research in investigative interviewing, Arena, Aldershot, England. 
McAfee, J, Cockram, J \& Wolfe, P (2001) 'Police reactions to crimes involving people with mental retardation: A cross-cultural experimental study', Education and Training in Mental Retardation and Developmental Disabilities, vol 36, no 2, pp 160-171.

McGough, L (1994) Child witnesses: Fragile voices in the American legal system, Yale University Press, New Haven.

Milne, R \& Bull, R (1999) Investigative interviewing: Psychology and practice, Wiley, Chichester.

NSPCC, Joseph Rowntree Foundation \& Triangle (2001) Two-way street: Communicating with disabled children and young people [Videotape], available from NSPCC National Training Centre, 3 Gilmour Close, Beaumont Leys, Leicester, England, LE4 1EZ.

Orbach, Y, Hershowitz, I, Lamb, M, Sternberg, K, Esplin, P, \& Horowitz, D (2000) 'Assessing the value of structured protocols for forensic interviews of alleged child abuse victims', Child Abuse \& Neglect, vol 24, no 6, pp 733-752.

Perlman, N, Ericson, K, Esses, V, \& Isaacs, B (1994) 'The developmentally handicapped witness: Competency as a function of question format', Law and Human Behaviour, vol 18, no 2, pp 171-187.

Poole, D \& Lamb, M (1998) Investigative interviews of children, American Psychological Association, Washington.

Powell, M (2002) 'Specialist training in investigative and evidential interviewing: Is it having any effect on the behaviour of professionals in the field?', Psychiatry, Psychology, \& Law, vol 9, no 1, pp 44-55.

Powell, M (2000) 'Guidelines for conducting investigative interviews with Aboriginal people', Current Issues in Criminal Justice, vol 12, no 2, pp 181-197.

Powell, M \& McMeeken, L (1998) “ "Tell me about the time when ... ": Nine golden rules for interviewing a child about a multiple offence', Australian Police Journal, vol 52, no 2, pp 70-72.

Powell, M \& Thomson, D (in press) 'The makings of a reliable interview with a child witness', Australian Educational and Developmental Psychologist.

Reiner, R (1992) The politics of the police $\left(2^{\text {nd }}\right.$ ed.), Harvester Wheatsheaf, Hertfordshire.

Roberg, R \& Kuykendall, J (1990) Police organization and management: Behaviour, theory, and processes, Brooks/Cole, Pacific Grove.

Roberts, K \& Powell, M (2001) 'Describing individual incidents of sexual abuse: A review of research on the effects of multiple sources of information on children's reports', Child Abuse and Neglect, vol 25, no 12, pp 1643-1659.

Saywitz, K, Snyder, L \& Nathanson, R (1999) 'Facilitating the communicative competence of the child witness', Applied Developmental Science, vol 3, no 1, pp 58-68.

Sternberg, K, Lamb, M, Hershkowitz, I, Yudillevitch, L, Orbach, Y, Esplin, P \& Hovav, M (1997) 'Effects of introductory style on children's abilities to describe experiences of sexual abuse', Child Abuse \& Neglect, vol 21, pp 1133-1146. 
Sternberg, K, Lamb, M, Orbach, Y, Esplin, P \& Mitchell, S (2001) 'Use of a structured investigative protocol enhances young children's responses to free-recall prompts in the course of investigative interviews', Journal of Applied Psychology, vol 86, no 5, pp 9971005 .

Warren, A, Woodall, C, Thomas, M, Nunno, M, Keeney, J, Larson, S, \& Stadfeld, J (1999) 'Assessing the effectiveness of a training program for interviewing child witnesses', Applied Developmental Science, vol 3, pp 128-135.

Westcott, H (1994) 'The Memorandum of Good Practice and children with disabilities', Journal of Law and Practice, vol 3, no 2, pp 21-32.

Westcott, H \& Cross, M (1996) This far and no further: Towards ending the abuse of disabled children, Venture Press, Birmingham.

Westcott, H \& Davies, G (1996) 'Memorandum training in area child protection committees: A survey', Journal of Practice and Staff Development, vol 5, pp 48-64.

Westcott, H \& Jones, D (1999) 'Annotation: The abuse of disabled children', Journal of Child Psychology and Psychiatry, vol 40, no 4, pp 497-506.

Wilson, C \& Powell, M (2001) A guide to interviewing children: Essential skills for counsellors, police, lawyers and social workers, Allen and Unwin, New South Wales.

Wilson, J, Powell, M \& McMeeken, L (1999) 'Videotaping children's evidence: The costs and benefits', Australian Police Journal, vol 53, no 4, pp 246-249. 